\title{
Sequence Analysis of Alginate-Derived Oligosaccharides by Negative-Ion Electrospray Tandem Mass Spectrometry
}

\author{
Zhenqing Zhang, Guangli Yu, Xia Zhao, Haiying Liu, and Huashi Guan \\ Institute of Marine Drug and Food, Ocean University of China, Shandong, China \\ Alexander M. Lawson and Wengang Chai \\ MRC Glycosciences Laboratory, Faculty of Medicine, Imperial College London, Middlesex, United Kingdom
}

\begin{abstract}
Negative-ion electrospray tandem mass spectrometry (ES-MS/MS) with collision-induced dissociation (CID) is attempted for sequence determination of alginate oligosaccharides, derived from polyanionic alginic acid, polymannuronate, and polyguluronate by partial depolymerization using either alginate lyase or mild acid hydrolysis. Sixteen homo- and hetero-oligomeric fragments were obtained after fractionation by gel-filtration and strong anion exchange high performance liquid chromatography. The product-ion spectra of these alginate oligosaccharides were dominated by intense B-, C-, Y-, and Z-type ions together with ${ }^{0,2} \mathrm{~A}$ - and ${ }^{2,5} \mathrm{~A}$-ions of lower intensities. Internal mannuronate residues (M) produce weak but specific decarboxylated $Z_{\text {int }}$-ions $\left(Z_{\text {int }}-44 \mathrm{Da}\right.$; int: denotes internal), which can be used for distinction of $\mathrm{M}$ and a guluronate residue $(\mathrm{G})$ at an internal position. A reducing terminal $\mathrm{M}$ or $\mathrm{G}$, although neither gives rise to a specific ion, can be identified by differences in the intensity ratio of fragment ions of the reducing terminal residue $\left[{ }^{2,5} \mathrm{~A}_{\text {red }}\right] /\left[{ }^{0,4} \mathrm{~A}_{\text {red }}\right]$ (red: denotes reducing terminal). (J Am Soc Mass Spectrom 2006, 17, 621-630) (c) 2006 American Society for Mass Spectrometry
\end{abstract}

\section{A} lginate, an acidic linear polysaccharide, occurs in brown algae and can also be formed as biofilms [1] by some bacteria, e.g., Azotobacter vinelandii and Pseudomonas aeruginosa $[2,3]$. Infection with the latter opportunistic pathogen seen in cystic fibrosis patients remains a major health concern [4]. Alginate consists of hexuronic acid residues $\beta$-Dmannuronic acid (M) and $\alpha$-L-guluronic acid $(\mathrm{G})$ with exclusively $1 \rightarrow 4$ glycosidic linkages. Along its linear chain, there are homo-oligomeric regions of mannuronate (M-blocks) and of guluronate (G-blocks) as well as hetero-oligomeric regions (MG-blocks) $[5,6]$. In contrast to algal alginate and alginate of $A$. vinelandii, the absence of G-blocks or low ratio of G- to M-blocks is characteristic for alginate from most bacteria such as $P$. aeruginosa. The alginate coat of $P$. aeruginosa is known to provide protection from immune defence system. Oligomannuronates have been shown to have an inhibitory effect on reactive oxidizing species production [7] from immune cells, whereas oligoguluronates with similar sizes did not exhibit any significant effect [8]. The physical properties of the alginates have also been well

Published online February 28, 2006

Address reprint requests to Dr. W. Chai, MRC Glycosciences Laboratory, Faculty of Medicine, Imperial College London, Northwick Park and St. Mark's Campus, Harrow, Middlesex HA1 3UJ, UK. E-mail: w.chai@ imperial.ac.uk, and also to G. Yu, Institute of Marine Drug and Food, Ocean University of China, Shandory, 26603 China. E-mail: glyu@ouc.edu.cn. documented and can be used as thermally stable cold setting gelling agents in the presence of calcium ions, gelling at far lower concentrations than gelatin. High G content produces strong, brittle gels with good heat stability whereas high $\mathrm{M}$ content produces weaker, more-elastic gels with good freeze-thaw behavior. Alginate oligosaccharide fragments and their derivatives have been widely used as releasing agents in the pharmacy [9], as additives in the food industry [10], and as growth-promoters in agriculture [11]. Recently, it has also found important applications in tissue engineering [12].

Polyanionic oligosaccharides such as those derived from glycosaminoglycans have attracted considerable interests recently because of the increased awareness of their functional properties. The functional properties of alginates and their oligosaccharide fragments are intimately linked to the composition ( $\mathrm{M} / \mathrm{G}$ ratio) and sequences of the hexuronic acid $M$ and $G$ residues. Methods for identification of oligosaccharides derived from the M-, G-, or MG-blocks, and their sequence determination, are important for better understanding the structure-function relationships of alginates at the molecular level. NMR spectroscopy has, for a long period of time, been the primary method for sequence analysis of alginate and derived oligosaccharides [13]. We have previously reported seven alginate-derived oligosaccharides by 1 - and 
2-D NMR [14, 15]. However, NMR requires relatively large amounts of materials, while mass spectrometric techniques have provided alternatives for composition analysis of alginate by molecular mass determination [14, 16-18]. Recently, sequence analysis of oligosaccharides by mass spectrometry has been of intense interest [19-21]. Electrospray (ES) ionization with collision-induced dissociation tandem mass spectrometry (CID-MS/MS) in the negative-ion mode has been successfully used for sequence determination of various types of carbohydrate molecules with high sensitivity. Unique fragmentation can arise at certain monosaccharide residues with specific linkages under CID-MS/MS conditions, and these provide important information on sequence and linkages. For instance, specific D-fragmentation for typing blood-group related Lewis $a / x$ and $b / y$ determinants and ${ }^{0,2} \mathrm{~A}$-cleavage for differentiation of type 1 and type 2 chains [22, 23], and the location of $\mathrm{N}$-unsubstituted glucosamine in a unique heparan sulphate motif $[24,25]$.

Alginate oligosaccharide fragments can be produced by either enzymatic digestion or controlled acid hydrolysis. Alginate lyases have been widely used for degradation of alginates and the lyases cleave at the hexuronic acid residue sites releasing the 4,5-unsaturated hexuronic acid residue $(\Delta)$ at the nonreducing terminus. This unsaturation provides a UV chromophore (232 $\mathrm{nm})$ useful for chromatographic detection. Controlled acid hydrolysis results in random cleavage along the polysaccharide chains and produces oligosaccharide fragments with unmodified hexuronic acid residues at both termini. Low pressure gel permeation chromatography (LP-GPC) combined with strong-anion exchange high-performance liquid chromatography (SAX-HPLC) have been the choice of separation and purification of alginate-derived oligosaccharides.

In the present report, we isolated and purified fifteen alginate oligosaccharides, including lyase-derived $\Delta \mathrm{GG}, \Delta \mathrm{MG}, \Delta \mathrm{MM}, \Delta \mathrm{GGG}, \Delta \mathrm{MMM}, \Delta \mathrm{MGG}$, and $\triangle G M G$, and acid hydrolysis-derived MM, MMM, MMMM, MMMMM, GG, GGG, GGGG, and GGGGG. These alginate-derived oligosaccharides were characterized by ${ }^{1} \mathrm{H}-\mathrm{NMR}$ before analysis by ES-CID-MS/MS.

\section{Experimental}

\section{Materials}

Alginate (L. Japonica, with a ratio of M/G: 2.28), and polymannuronate and polyguluronate (both prepared from alginate, with an average molecular weight 10,000 Da) were purchased from Huahai Pharmaceutical Industry (Qingdao, China). Gel-filtration media Bio-Gel P6 (fine, $45 \mu \mathrm{m}, 26 \times 1000 \mathrm{~mm}$ ) was from BioRad (Richmond, CA) and Sephadex G-10 from Amersham Biosciences (Uppsala, Sweden). SAX-HPLC was performed on Spherisorb S5 SAX $(20 \times 250 \mathrm{~mm})$ column (Clwyd, U.K.). Silica Gel 60 high-performance (HP) TLC plates $(20 \times 20 \mathrm{~cm}$, with aluminium backing $)$ were purchased from Merck (Darmstadt, Germany).

\section{Preparation of Alginate-Derived Oligosaccharide Fragments}

Alginate oligosaccharides with nonreducing terminal unsaturated hexuronic acid residues were obtained by partially degradation of alginate with alginate lyase (from Vibrio sp. 510) as described [14]. Briefly, alginate $(5 \mathrm{~g})$ was dissolved in $1000 \mathrm{ml}$ of $50 \mathrm{mM}$ Tris- $\mathrm{HCl}$ buffer $(\mathrm{pH} 7.5)$ and 50 units alginate lyase were added. The reaction was carried out at $28^{\circ} \mathrm{C}$ for $24 \mathrm{~h}$.

Saturated alginate oligosaccharides were obtained from polymannuronate or polyguluronate by mild acid partial hydrolysis. Each polysaccharide (5 g) was dissolved in $500 \mathrm{ml} 2 \mathrm{M} \mathrm{HCl}(\mathrm{pH} \mathrm{4})$ in double distilled water. The hydrolysis reaction was carried out at $120^{\circ} \mathrm{C}$ for $3 \mathrm{~h}$ and then cooled to room-temperature and neutralized to $\mathrm{pH} 7$; the solution was rotary evaporated and desalted with Sephadex G-10 column $(35 \times 850$ $\mathrm{mm}$ ) and lyophilized.

The reaction mixture (typically $2 \mathrm{ml}, 100 \mathrm{mg} / \mathrm{ml}$ ) obtained from either lyase or acid hydrolysis was loaded onto a Bio-Gel P6 column $(2.6 \times 100 \mathrm{~cm})$ and eluted by $0.5 \mathrm{M} \mathrm{NH}_{4} \mathrm{HCO}_{3}$ at a flow rate of $15 \mathrm{ml} / \mathrm{h}$ at room temperature. Eluate was monitored on-line by a refractive index detector (Gilson 132) and collected by auto-fraction collector ( $2 \mathrm{ml} /$ tube, RediFrac, Pharmacia). Fractions were pooled according to size and freezedried before further analysis.

The oligosaccharide fractions obtained from polymannuronate or polyguluronate were rechromatographed twice on the same column and pure homooligosaccharide fractions, MM, MMM, MMMM, MMMMM, GG, GGG, GGGG, GGGGG, obtained. The gel-filtration fractions of oligosaccharides derived from lyase digestion were further fractionated by preparative SAX-HPLC as described [14], and seven unsaturated oligosaccharides, $\Delta \mathrm{G}, \Delta \mathrm{GG}, \Delta \mathrm{MG}, \Delta \mathrm{GGG}, \Delta \mathrm{MGG}$, $\Delta G M G$, and $\triangle M M M$ were obtained. The unsaturated mannuronic acid trisaccharide $\Delta \mathrm{MM}$ was prepared from homo mannuronate by alginate lyase from Pseudoalteromonas sp. Strain No. 272 [15]. Further purification of the hetero-oligosaccharides was carried out on HPLC with an analytical SAX column.

\section{High Performance Thin Layer Chromatography}

The purity of alginate-derived oligosaccharides was checked on a silica gel high-performance TLC plate $(3 \times$ $5 \mathrm{~cm}$ ) developed with a solvent system of $n$-butanol/ formic acid/water, 4:6:1 (vol/vol) [26]. The developed plate was stained by dipping in cerium sulphate reagent $(0.02 \%$ cerium sulphate crystal, $0.05 \%$ ammonium molybdate, and $5 \% \mathrm{H}_{2} \mathrm{SO}_{4}$ in $\mathrm{EtOH}$ ) for $3 \mathrm{~s}$ and heated at $100{ }^{\circ} \mathrm{C}$ for $10 \mathrm{~s}$. 


\section{NMR Spectroscopy}

Polymannuronate and polyguluronate samples were coevaporated by lyophilization twice with $1 \mathrm{ml}$ of $\mathrm{D}_{2} \mathrm{O}(99.96 \%)$ to remove exchangeable protons before final dissolution in $0.5 \mathrm{ml}$ of $\mathrm{D}_{2} \mathrm{O}$ for NMR analysis. ${ }^{1} \mathrm{H}$ and ${ }^{13} \mathrm{C}-\mathrm{NMR}$ spectra were acquired from a JEOL ECP $600 \mathrm{MHz}$ spectrometer performed at $298 \mathrm{~K}$ as described [14, 15].

\section{Oligosaccharide Reduction}

To the freeze-dried oligosaccharide (typically $20-50 \mu \mathrm{g}$ ) was added $20 \mu \mathrm{l}$ of $\mathrm{NaBD}_{4}$ reagent $\left(0.05 \mathrm{M} \mathrm{NaBD}{ }_{4}\right.$ in $0.01 \mathrm{M} \mathrm{NaOH}$ ) and the reduction was carried out at $4{ }^{\circ} \mathrm{C}$ overnight as described [19]. The reaction solution was then neutralized to $\mathrm{pH} 7$ with a solution of $\mathrm{AcOH} / \mathrm{H}_{2} \mathrm{O}$ (1:1) to destroy borodeuteride before passing through a mini-column of cation exchange (AG50W-X8, H form, Bio-Rad, Hemel Hempstead, England). Boric acid was removed by repeated co-evaporation with $\mathrm{MeOH}$.

\section{Electrospray Mass Spectrometry}

Negative-ion ESMS was carried out on a Micromass Q-TOf and a Q-TOf Ultima instruments (Waters, Manchester, UK) in the negative-ion mode. Nitrogen was used as the desolvation and nebulizer gas at a flow rate of 250 and $15 \mathrm{l} / \mathrm{h}$, respectively. Source temperature was $80^{\circ} \mathrm{C}$ and the desolvation temperature was $150{ }^{\circ} \mathrm{C}$. For high sensitivity ES-MS analysis, all sodium ions in oligosaccharides were converted to ammonium ions with a short column of cation exchange (AG50W-X8, H form) as described previously [19]. Samples were dissolved in acetonitrile/1 $\mathrm{mM} \mathrm{NH}_{4} \mathrm{HCO}_{3}(1: 1, \mathrm{vol} / \mathrm{vol})$, typically at a concentration of $\sim 5-10 \mathrm{pmol} / \mu \mathrm{l}$, of which $5 \mu \mathrm{l}$ was loop-injected. Mobile phase (acetonitrile/1 $\mathrm{mM} \mathrm{NH}_{4} \mathrm{HCO}_{3}$ 1:1, vol/vol) was delivered by a syringe pump at a flow rate of $10 \mu \mu \mathrm{l} / \mathrm{min}$. Cone voltage was maintained at $50 \mathrm{eV}$ while capillary voltage was at $3 \mathrm{kV}$. For collision-induced dissociation (CID) MS/MS production scanning, a cone voltage of $80 \mathrm{eV}$ was employed to maximize the intensity of singly charged molecular ion. Argon was used as the collision gas at a pressure of 1.7 bar and the collision energy was adjusted between 25-42 eV for optimal sequence information.

\section{Results and Discussion}

Alginate oligosaccharides were prepared by partial depolymerization of polysaccharides obtained from different sources by two methods. The guluronate and mannuronate homo-oligomers, di- to pentasaccharides, were obtained from mild acid hydrolysis of the respective homo-polysaccharides. The quality of the parent homo-polysaccharides was determined by ${ }^{1} \mathrm{H}$ and ${ }^{13} \mathrm{C}-\mathrm{NMR}$ spectroscopy (Figure 1 ). The difference between G-blocks (with $\alpha$-linkages) and $\mathrm{M}$ blocks (with $\beta$-linkages) in ${ }^{1} \mathrm{H}$-NMR spectra (Figure 1a) was apparent from the chemical shifts of $\mathrm{H}-1$ (5.03 and $4.62 \mathrm{ppm}$, respectively) and $\mathrm{H}-5$ (4.44 and 3.74 ppm, respectively). The chemical shifts in ${ }^{13} \mathrm{C}-\mathrm{NMR}$ spectra (Figure $1 \mathrm{~b}$ ) of C-5 of G- and M-blocks were also distinctive (68.66 and $75.86 \mathrm{ppm}$, respectively). Individual homo-oligosaccharide fragments were obtained by repeated fractionation of gel-filtration chromatography. HPTLC was used for analysis for purity of the homo-oligosaccharides obtained. As examples, dito penta-mannuronates and -guluronates were shown in Figure 2. Each oligosaccharide fraction gave a symmetrical blue dot on HPTLC plates. There was no difference in retention time between saturated mannuronate and guluronate oligosaccharides of the same chain length. The hetero-oligosaccharide fragments were obtained by alginate lyase digestion of alginic acid and purified by gel-filtration and HPLC using SAX column as previously described [14].

Negative-ion ES-CID-MS/MS was initially assessed with various pseudomolecular ions, including $[\mathrm{M}-\mathrm{H}]^{-},[\mathrm{M}-2 \mathrm{H}]^{2-}$, and $[\mathrm{M}-2 \mathrm{H}+\mathrm{Na}]^{-}$, as precursors for optimal sequence information. Production spectra of $[\mathrm{M}-\mathrm{H}]^{-}$were chosen for the study as other precursors did not produce fragments that were more structurally informative. The trisaccharides M3 and G3 were used first for investigation of the fragmentation patterns, and the principles established were then used for sequence determination of other homo- and hetero-oligosaccharides.

\section{Trisaccharides M3/G3}

In the product-ion spectra of G3 and M3 (Figure 3a and b), the major ions $m / z 369,193$, and 175 are produced from single glycosidic bond cleavage and can be assigned as $C_{2} / Y_{2}, C_{1} / Y_{1}$, and $B_{1} / Z_{1}$ [27], respectively, derived from either the reducing or nonreducing termini, indicating linear sequences HexA-HexA-HexA. Weak A-type ions, e.g., ${ }^{0,2}(\mathrm{~m} / \mathrm{z} 309$ and 485; note the $\times 5$ magnification factor applied to specific regions), ${ }^{2,5} \mathrm{~A}$ $\left(\mathrm{m} / \mathrm{z} 291\right.$ and 467), and ${ }^{0,4} \mathrm{~A}_{3}$ ions $(\mathrm{m} / \mathrm{z} 471)$ are also observed in both spectra. As two A-type ions $\left({ }^{0,2} \mathrm{~A}\right.$ and ${ }^{2,5} \mathrm{~A}$ ) arise from cleavage at carbon-carbon bond 2 of the saccharide ring (see fragmentation schemes in Figure 3) this excludes the possibility of glycosidic linkages at 2-positions. The absence of a double glycosidic cleavage, which is unique to a 3-linked chain [22, 23], and the presence of a carboxyl group at the 6-position suggest that the likely HexA linkage is at 4-position. Differentiation of a fragment ion derived from a reducing or a nonreducing terminus can be made by comparison of product-ion spectra of the reducing sugar and reduced alditol (see Figure 3c for the alditol of M3). A reducing terminal ion should have a $3 \mathrm{Da}$ increment following reduction with borodeuteride while a nonreducing terminal ion remains unchanged. As shown in Figure 3c, the A-type ions of the reducing terminal residue $(\mathrm{m} / \mathrm{z}$ 467,471 , and 485) disappears as these are generated 
(a) ${ }^{1} \mathrm{H}-\mathrm{NMR}$



(b) ${ }^{13} \mathrm{C}-\mathrm{NMR}$

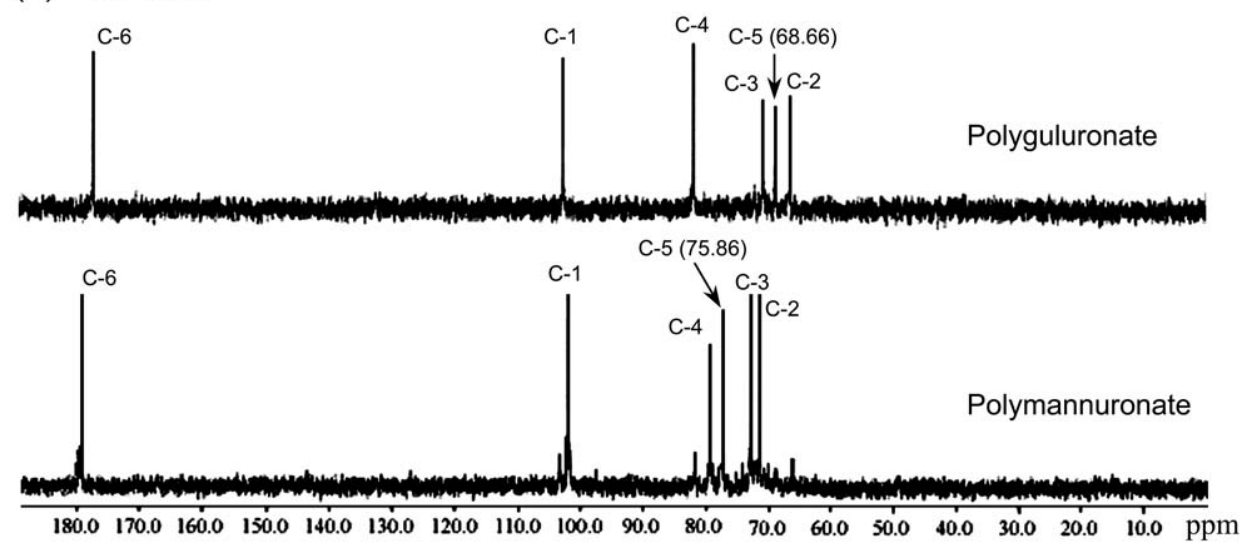

Figure 1. $\quad{ }^{1} \mathrm{H}$ and ${ }^{13} \mathrm{C}-\mathrm{NMR}$ spectra of polyguluronate and polymannuronate. (a) ${ }^{1} \mathrm{H}-\mathrm{NMR}$ spectra of polyguluronate and polymannuronate; (b) ${ }^{13} \mathrm{C}-\mathrm{NMR}$ of polyguluronate and polymannuronate.

(a)

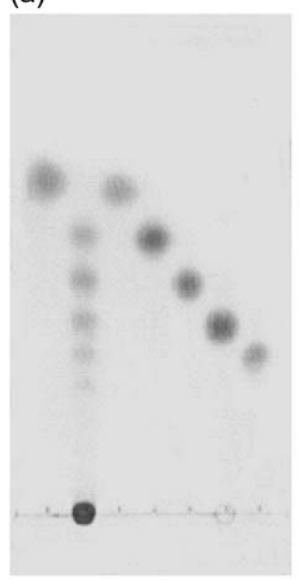

$\begin{array}{lllllll}1 & 2 & 3 & 4 & 5 & 6 & 7\end{array}$ (b)

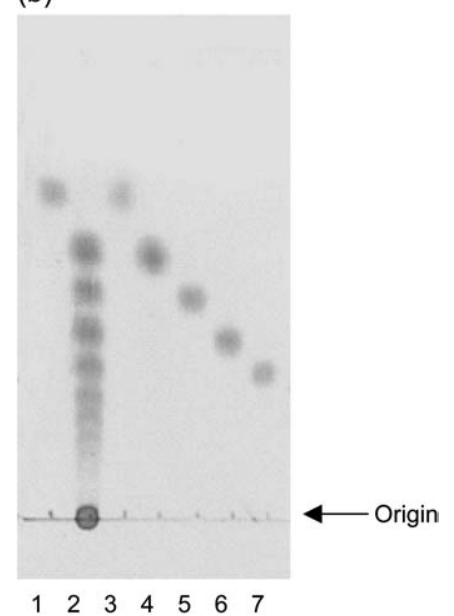

Figure 2. HPTLC of guluronate- and mannuronate-oligosacchrides. (a) Lane 1, D-glucuronic acid; lane 2, oligoguluronate mixture; lanes 3-7, mono- to pentasaccharides of guluronate, respectively. (b) Lane 1, D-glucuronic acid; lane 2, oligomannuronate mixture; lanes $3-7$, mono- to pentasaccharides of mannuronate, respectively.

from cross-ring cleavage and cannot form after reductive ring opening.

Nonreducing terminal $\mathrm{M}$ and $\mathrm{G}$ give identical ions $\mathrm{C}_{1}(\mathrm{~m} / \mathrm{z} 193), \mathrm{B}_{1}(\mathrm{~m} / \mathrm{z} 175)$ together with the dehydrated and decarboxylated ions $(\mathrm{m} / \mathrm{z} 157$ and $\mathrm{m} / \mathrm{z}$ 131) (Figure $3 a$ and $b$ ), and thus it is not possible to differentiate the two residues at a nonreducing terminus. However, identification of the two residues at an internal or reducing terminal position can be made by careful comparison of some specific, although weak, fragment ions. An internal M produces a unique ion at $\mathrm{m} / \mathrm{z} 307$ (Figure 3b) whereas an internal G does not (Figure 3a). The ion $\mathrm{m} / \mathrm{z} 307$ can be explained by either a decarboxylated $\mathrm{Z}_{2}\left(\mathrm{Z}_{2}-\mathrm{CO}_{2}\right)$ or decarboxylated $\mathrm{B}_{2}\left(\mathrm{~B}_{2}-\mathrm{CO}_{2}\right)$. However, the product-ion spectrum of the resulting alditol (Figure 3c) unambiguously indicates that this ion is derived from the reducing terminus as $\mathrm{Z}_{2}-\mathrm{CO}_{2}$ because only a reducing terminal ion could have a $3 \mathrm{Da}$ increment following reduction with borodeuteride $(\mathrm{m} / \mathrm{z}$ 307 shifted to $m / z$ 310, compare Figure $3 \mathrm{~b}$ and $c$ ). This unique fragmentation occurs only for an $\mathrm{M}$ located at an internal position.

Decarboxylation cannot be used as a criterion to differentiate $\mathrm{M} / \mathrm{G}$ at either the reducing or nonreducing 

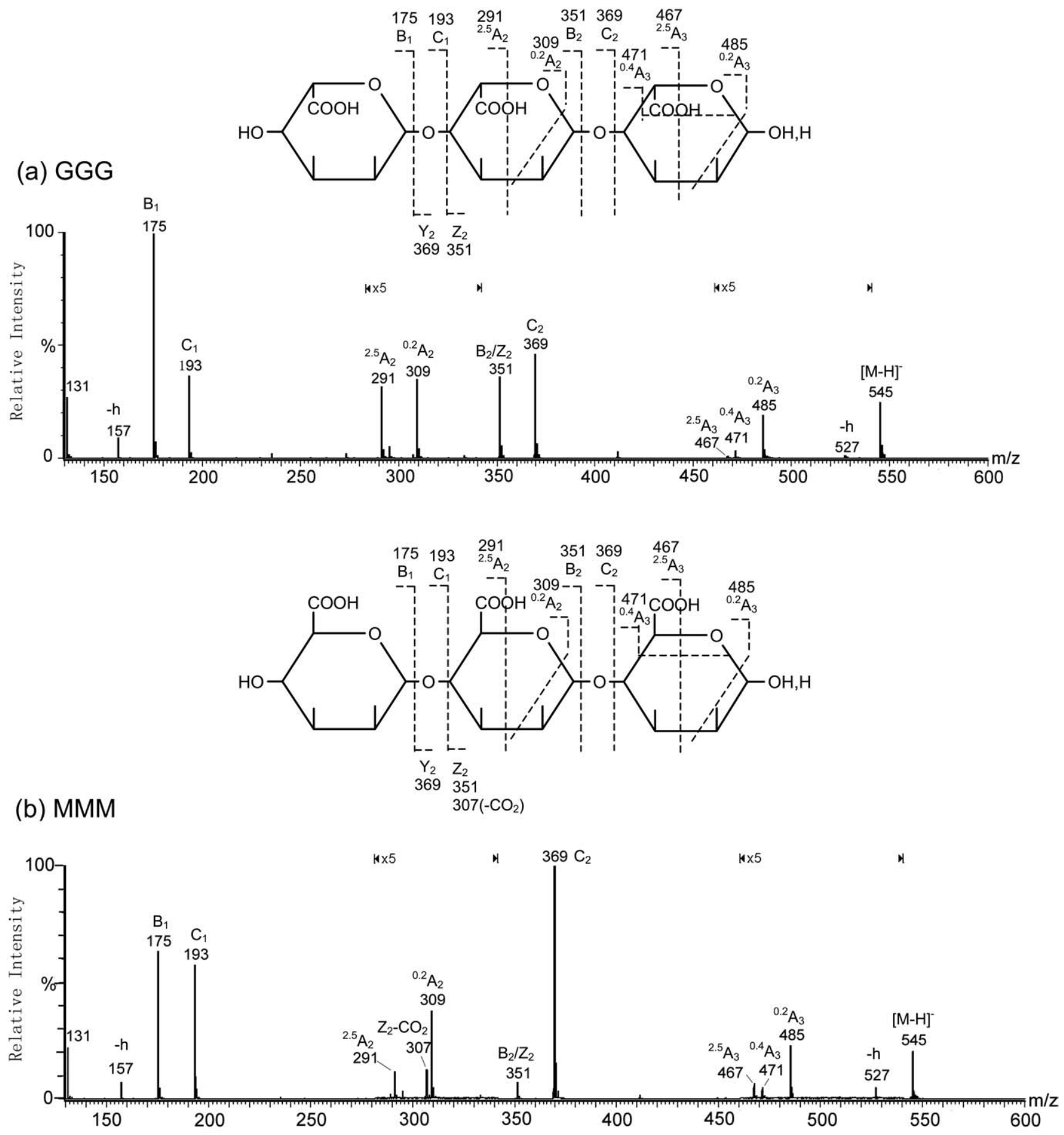

(c) MMM-ol

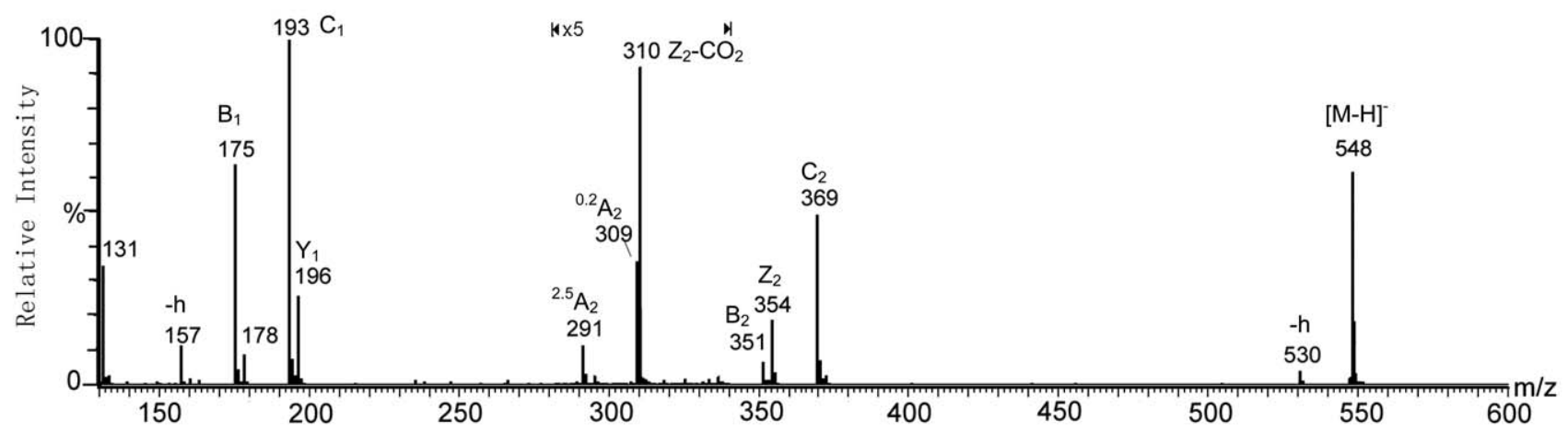

Figure 3. Negative-ion ES-CID-MS/MS product-ion spectra of G3 and M3. (a) G3, (b) M3, and (c) $\mathrm{M} 3-\mathrm{ol}$. Structures are shown to indicate the proposed fragmentation (-h: dehydrated ion). 
termini, as decarboxylation is not observed for $\mathrm{M}$ at a reducing terminus while a decarboxylated $\mathbf{B}_{1}(\mathrm{~m} / \mathrm{z} 131)$ is observed for both $M$ and $G$ at the nonreducing termini. However, a reducing terminal $\mathrm{M}$ can be assigned by careful comparison of the intensity ratio of two weak reducing terminal ions, ${ }^{2,5} \mathrm{~A}_{3}(\mathrm{~m} / \mathrm{z} 467)$ and ${ }^{0,4} \mathrm{~A}_{3}(m / z 471)$; a higher $\left[{ }^{2,5} \mathrm{~A}_{3}\right] /\left[{ }^{0,4} \mathrm{~A}_{3}\right]$ ratio (1.65, Table 1 and Figure $3 b)$ indicates $M$ while a lower one $(0.20$, Table 1 and Figure 3a) indicates G.

\section{Disaccharides M2/G2}

CID MS/MS of the disaccharides M2 and G2 show similar features (Table 1, spectra not shown) to those of the trisaccharides. Both disaccharides give product-ion spectra with fragments $B_{1}, C_{1},{ }^{0,2} A_{2}, B_{2}, C_{2}, Z_{1}$, and $Y_{1}$ ions (Table 1). As there are no internal residues, decarboxylated $\mathrm{Z}$ ion $\left(\mathrm{Z}_{\text {int }}-\mathrm{CO}_{2}\right)$ was absent. However, both reducing terminal $M$ and $G$ produce weak ${ }^{2,5} \mathrm{~A}_{2}(\mathrm{~m} / \mathrm{z}$ 291) and ${ }^{0,4} \mathrm{~A}_{2}(m / z 295)$ ions and the intensity ratios $\left[{ }^{2,5} \mathrm{~A}_{2}\right] /\left[{ }^{0,4} \mathrm{~A}_{2}\right]$ can be used for the differentiation of an $\mathrm{M}$ from a $\mathrm{G}$ at this position. A higher ratio (3.5, Table 1) in the spectrum of $\mathrm{M} 2$ suggests a reducing terminal $\mathrm{M}$, whereas a lower ratio $(0.55$, Table 1$)$ in the spectrum of G2 suggests a reducing terminal $G$, as discussed above for the trisaccharides.

\section{Tetrasaccharides M4/G4 and Pentasaccharides M5/G5}

Two pairs of homo-oligomers M4/G4 and M5/G5 were also analyzed in the same way as the trisaccharides. For illustration, the spectra of G5 and M5 are shown in Figure 4 (again note the magnification factors of specific mass regions). As expected, their linear sequence can be readily derived from the major fragment ions $\mathrm{m} / \mathrm{z}$ $175 / 193,351 / 369,527 / 545,703 / 721$ arising by glycosidic bond cleavages. The cross ring cleavage ions ${ }^{0,2} \mathrm{~A}$ for 4-linked hexuronic acid residues are also present. The reducing terminal M in both M4 and M5 can be identified by the higher ratio $(0.80$ in both cases, Table 1) of $\left[{ }^{2,5} \mathrm{~A}_{\text {red }}\right] /\left[{ }^{0,4} \mathrm{~A}_{\text {red }}\right]$ (red: reducing terminal) compared with a reducing terminal residue G in G4 and G5 (0.15-0.20, Table 1). The internal $\mathrm{M}$ can be assigned by the presence of the unique $\mathrm{Z}_{\text {int }}-\mathrm{CO}_{2}$ ions (e.g., $m / z 307$, 483, and 659 in M5, Figure 4b). However, as shown in spectrum of M5 (Figure 4b), for a longer oligosaccharide chain, the $M$ residue next to the reducing terminus produces the strongest $\mathrm{Z}_{\mathrm{int}}-\mathrm{CO}_{2}$ ion, whereas an internal $\mathrm{M}$ next to the nonreducing terminus produces the weakest.

\section{Unsaturated Hetero-, Tri-, and Tetrasaccharides}

Seven hetero-, tri-, and tetrasaccharides with unsaturated nonreducing terminal hexuronic acid residues and mixed compositions of $\mathrm{G}$ and $\mathrm{M}$, obtained from lyase digestion of alginate, were used to assess the method

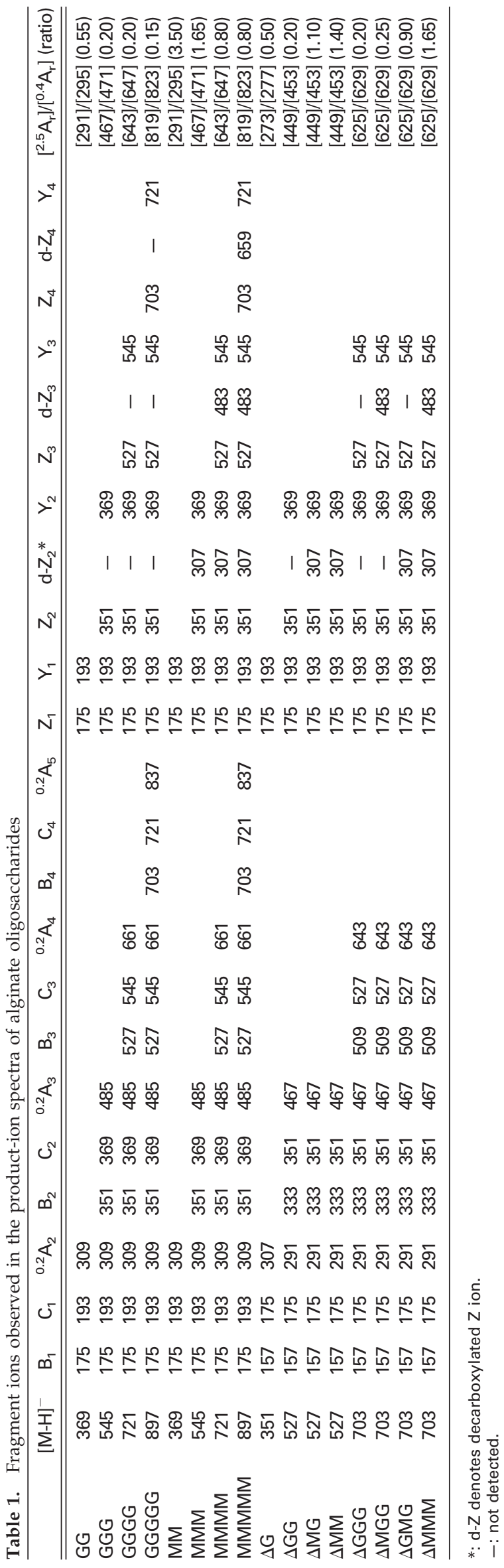




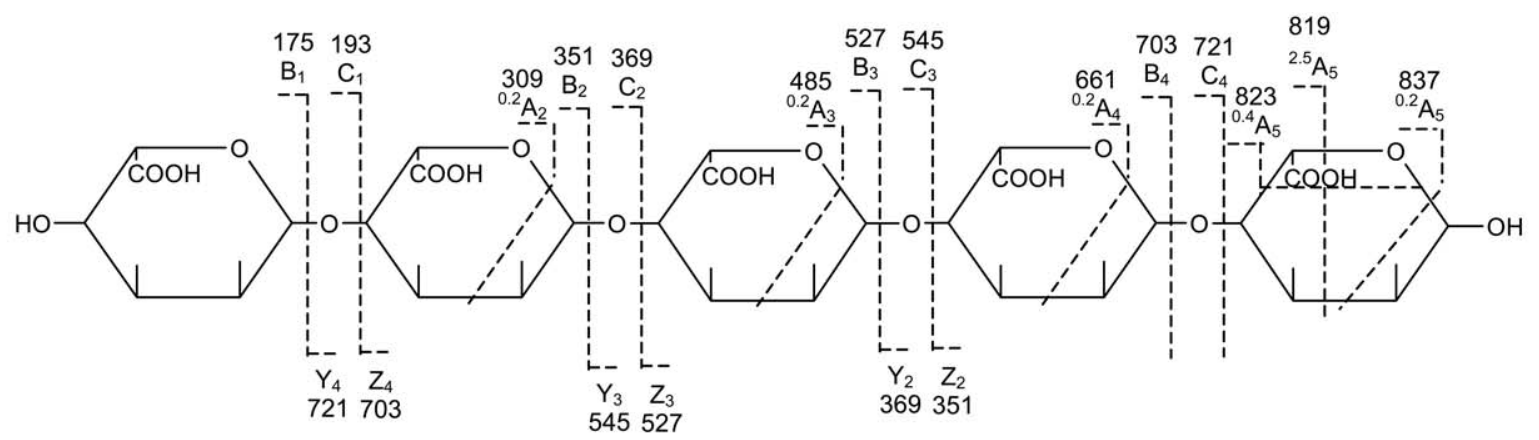

(a) G5

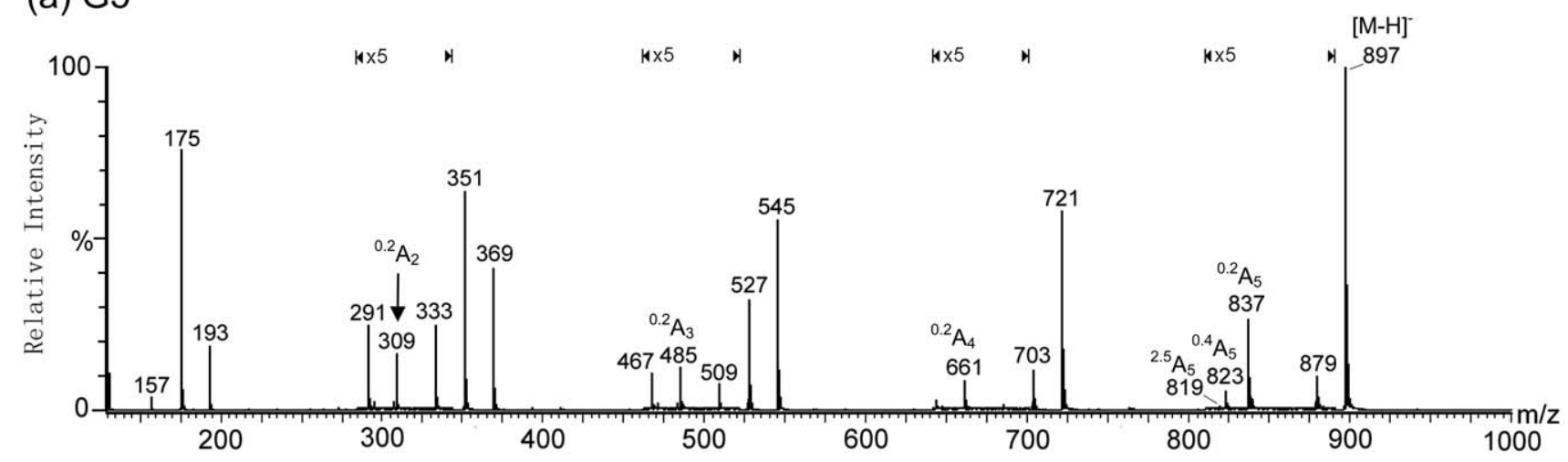

(b) M5
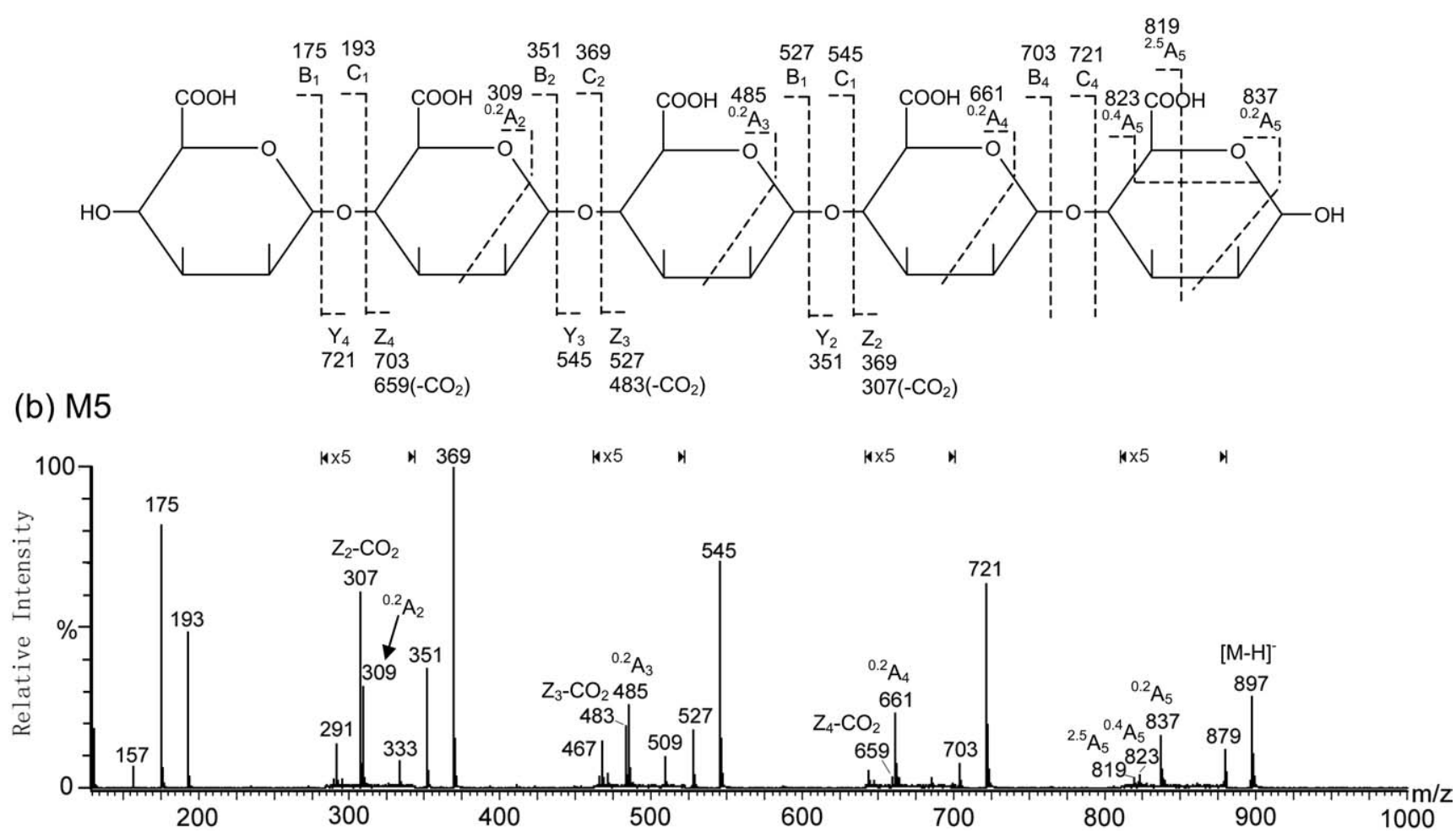

Figure 4. Negative-ion ES-CID-MS/MS product-ion spectra of G5 and M5. (a) G5 and (b) M5. Assignments of the ions are shown in the fragmentation schemes. Only the characteristic ions $\mathrm{Z}-\mathrm{CO}_{2}$,

${ }^{2,5} \mathrm{~A}_{5}$, and ${ }^{0,4} \mathrm{~A}_{5}$ are marked in the spectra.

established with the homo-oligosaccharides for sequence analysis. The tri- and tetrasaccharide sequences of $\Delta \mathrm{GG}, \Delta \mathrm{MG}, \Delta \mathrm{MM}, \Delta \mathrm{GGG}, \Delta \mathrm{MGG}, \Delta \mathrm{GMG}$, and $\triangle \mathrm{MMM}$ were initially characterized by NMR as described [14]. As expected, the major features of the product-ion spectra of tetrasaccharides $\Delta G G G$ and 
(a) $\triangle M M M$
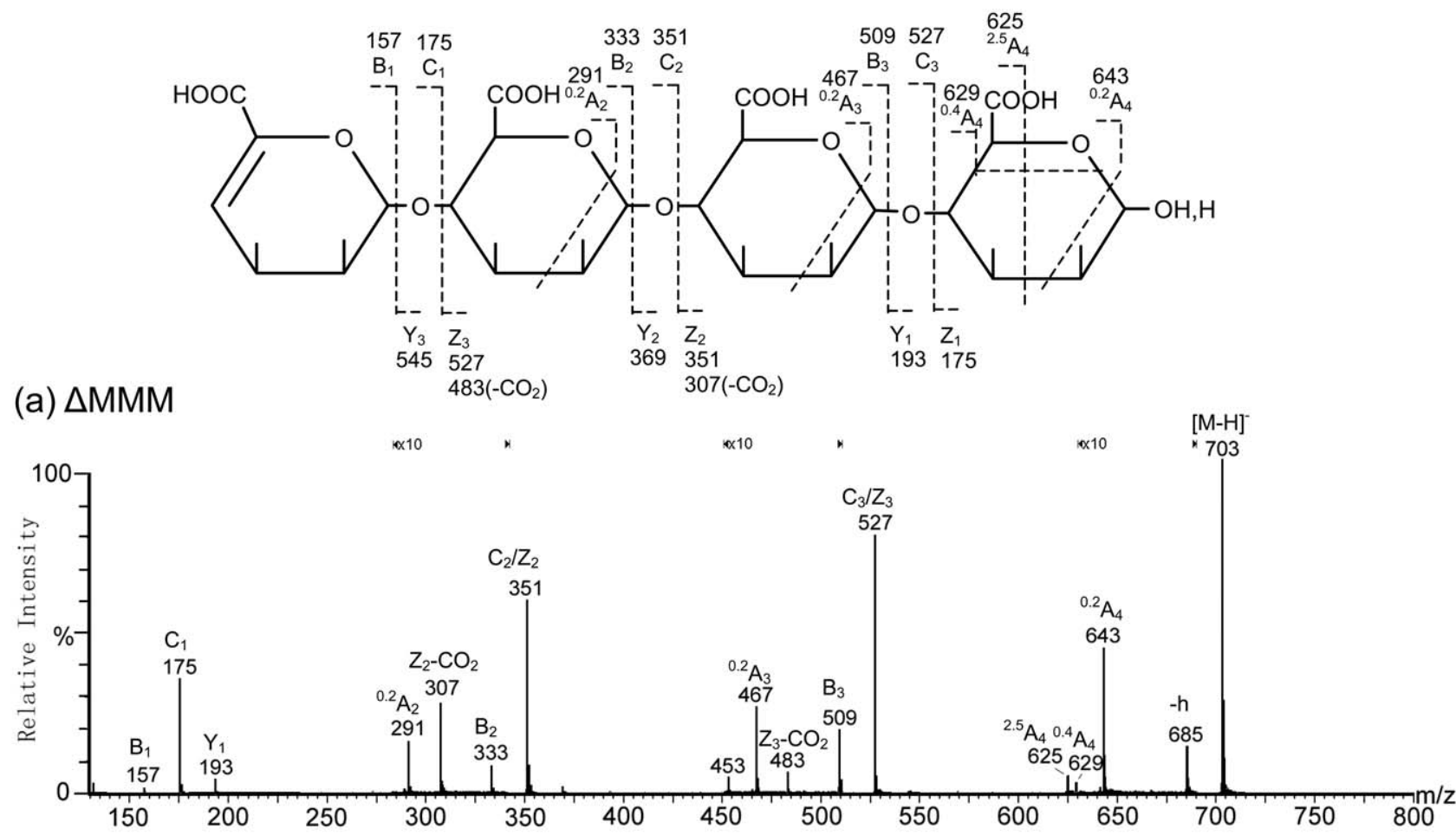

(b) $\triangle \mathrm{GMG}$
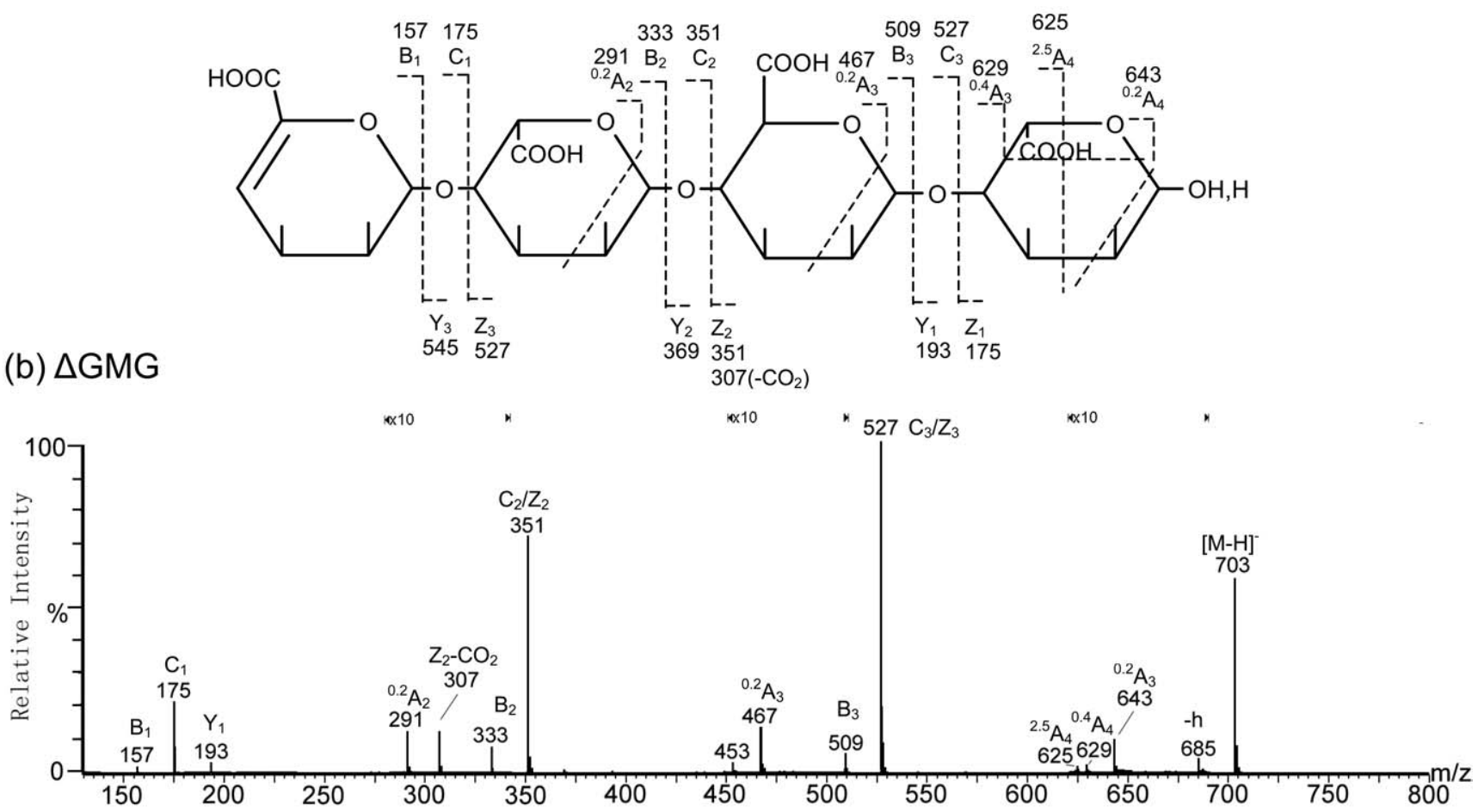

Figure 5. Negative-ion ES-CID-MS/MS product-ion spectra of $\triangle M M M$ and $\Delta G M G$. (a) $\Delta M M M$ and

(b) $\triangle$ GMG. Structures were shown to indicate the proposed fragmentation ( $-\mathrm{h}$ : dehydrated ion).

$\Delta$ MMM (Table 1) are similar to those of G4 and M4 apart from the $18 \mathrm{Da}$ mass shift of all the nonreducing terminal A-, B, and C-types ions due to the unsaturated form of the terminal hexuronic acid residue, while the reducing terminal fragment ions are identical to the saturated analogs. The $\mathrm{Z}_{\text {int }}-\mathrm{CO}_{2}$ ions (e.g., $m / z 307$ and 483 , Table 1$)$ and higher $\left[{ }^{2,5} \mathrm{~A}_{\text {red }}\right] /\left[{ }^{0,4} \mathrm{~A}_{\text {red }}\right]$ ratio (1.65, Table 1 ) in the spectrum of $\Delta \mathrm{MMM}$ (Figure $5 \mathrm{~b}$ ) again indicate internal and reducing terminal $M$ residues, respectively. 
In the case of $\Delta \mathrm{GMG}$ and $\Delta \mathrm{MGG}$, the two internal residues are different, and this is reflected by the $\mathrm{Z}_{\text {int }}-$ $\mathrm{CO}_{2}$ ions. In the spectrum of $\triangle \mathrm{GMG}$ (Figure $5 \mathrm{a}$ and Table 1), a $\mathrm{Z}_{2}-\mathrm{CO}_{2}$ at $\mathrm{m} / \mathrm{z} 307$ is present and $\mathrm{Z}_{3}-\mathrm{CO}_{2}$ $(\mathrm{m} / \mathrm{z} 483)$ is absent, whereas in the spectrum of $\Delta$ MGG (not shown) the $m / z 307$ is absent and $m / z 483$ is present (Table 1, spectrum not shown) indicating $M$ next to the nonreducing terminal $\Delta$ residue. Thus, this isomeric pair can be readily differentiated. The trisaccharides $\Delta \mathrm{GG}, \Delta \mathrm{MG}$, and $\Delta \mathrm{MM}$ can be similarly distinguished (Table 1).

\section{Conclusions}

ES-CID-MS/MS was assessed for sequence determination of alginate oligosaccharides. The product-ion spectrum is dominated by intense $\mathrm{B}-, \mathrm{C}-, \mathrm{Y}-$, and Z-type ions together with weak ${ }^{0,2} \mathrm{~A}$-ions. An internal mannuronate residue $M$ produces a specific decarboxylated $Z_{\text {int }}-$ $\mathrm{CO}_{2}$ ions (at $44 \mathrm{Da}$ lower in mass than the respective Z-ion, e.g., $m / z 307$ and 483 ). When $\mathrm{M}$ is at the reducing terminus a higher intensity ratio of $\left[{ }^{2,5} \mathrm{~A}_{\text {red }}\right] /\left[{ }^{0,4} \mathrm{~A}_{\text {red }}\right]$ is normally found. These unique low abundance ions can be used for differentiation of internal and reducing terminal $\mathrm{M}$ from $\mathrm{G}$ residues at these positions.

Differential decarboxylation has been reported for differentiation of isomeric structures of acidic oligosaccharides, e.g., weak ions produced by decarboxylation of 2-6 linked sialic acid has been observed and used for $\alpha 2-3 / \alpha 2-6$ linkage analysis of sialylated oligosaccharides $[28,29]$. Decarboxylation is a unimolecular process initiated by proton abstraction under alkaline conditions. In negative-ion electrospray mass spectrometry, deprotonated alginate oligosaccharide molecules in the gas phase undergo similar unimolecular decomposition. The slightly more acidic $\mathrm{M}\left(\mathrm{pK}_{\mathrm{a}} 3.38\right)$ [30] tends to lose $\mathrm{CO}_{2}$ more readily and produce decarboxylated fragment ions $Z_{\text {int }}-\mathrm{CO}_{2}$, whereas for a $\mathrm{G}\left(\mathrm{pK}_{\mathrm{a}}\right.$ 3.65) decarboxylation is less favorable and the respective ion is absent. The involvement of its carboxyl in the hydrogen bonding (see the structures below) is probably responsible for stabilization of the carboxyl group.

Other differences in fragmentation are also likely to arise from the influence of the internal hydrogen bonding in the preferred conformations of these structures. A D-mannuronate prefers a 3-fold left-handed helix with weak intra-molecular hydrogen bonding between the $3-\mathrm{OH}$ group and the ring oxygen of the adjacent residue of the nonreducing side, whereas a L-guluronate forms stiffer 2-fold screw helical chains through intramolecular hydrogen bonding between the carboxyl group and the 2-OH of the reducing side [31-33]. This influences the extent of cross ring fragmentations ${ }^{2,5} \mathrm{~A}_{\text {red }}$ and ${ }^{0,4} \mathrm{~A}_{\text {red }}$. Hence, it is not unexpected that fragmentation is more favorable for a reducing terminal $G$ and more favorable for a terminal $\mathrm{M}$.

\section{Acknowledgments}

This study was supported in part by a National Basic Research Program of China (2003CB716401), a National Science Foundation of China project grant (30370345), OUC Luka program (1405814147), and a U.K. Medical Research Council program grant (G9601454).

\section{References}

1. Costerton, J. W.; Stewart, P. S.; Greenberg, E. P. Bacterial Biofilms: A Common Cause of Persistent Infections. Science 1999, 284, 1318-1322.

2. Evans, L. R.; Linker, A. Production and Characterization of the Slime Polysaccharide of Pseudomonas aeruginosa. J. Bacteriol. 1973, 116, 915-924.

3. Rehm, B. H. A.; Valla, S. Bacterial Alginates: Biosynthesis and Applications. Appl. Microbiol. Biotechnol. 1997, 48, 281-288.

4. Cobb, L. M.; Mychaleckyj, J. C.; Wozniak, D. J.; Lopez-Boado, Y. S. Statistical Methods-A More Detailed Description of the Statistical Methods Used for Microarray Analysis. J. Immunol. 2004, 173, 56595670 .

5. Haug, A.; Larsen, B.; Smidsrod, O.A Study of the Constitution of Alginic Acid by Partial Acid Hydrolysis. Acta Chem. Scand. 1966, 20, 183-190.

6. Haug, A.; Larsen, B.; Smidsrod, O.; Painter, T. Studies on the Sequence of Uronic Acid Rresidues in Alginic Acid.. Acta Chem. Scand. 1969, 23, 2955-2962.

7. Darvill, A.; Augur, C.; Bergmann, C.; Carlson, R. W.; Cheong, J. J.; Eberhard, S.; Hahn, M. G.; Lo, M. V.; Marfa, V.; Meyer, B.; Mohnen, D.; O'Neil, M. A.; Spiro, M. D.; Halbeek; H. V.; York; W. S.; Albersheim, P. Amino-Sugar Glycosidase Inhibitors: Versatile Tools for Glycobiologists. Glycobiology 1992, 2, 181-198.

8. Bland, E. J.; Keshavarz, T.; Bucke, C. Towards Understanding the Interaction Between Oligosaccharides and Water Molecules. Carbohydr. Res. 2004, 339, 1673-1678.

9. Ci, S. X.; Huynh, T. H.; Louie, L. W.; Yong, A.; Beals, B. J.; Ron, N.; Tsang, W. G.; Soon-Shiang, P.; Desai, N. P. Molecular Mass Distribution of Sodium Alginate by High-Performance Size-Exclusion Chromatography. J. Chromatogr. A. 1999, 864, 199-210.

10. Johnson, F. A.; Craig, D. M.; Mercer, A. D. Characterization of the Block Structure and Molecular Weight of Sodium Alginates. J. Pharm. Pharmacol. 1997, 49, 639-643.

11. Fett, W. F.; Dunn, M. F. Exopolysaccharides Produced by Phytopathogenic Pseudomonas syringae Pathovar in Infected Leaves of Susceptible Hosts. Plant Physoil. 1989, 89, 5-9.

12. Kataoka, K.; Suzuki, Y.; Kitada, M.; Hashimoto, T.; Chou, H.; Bai, H. L.; Ohta, M.; Wu, S.; Suzuki, K.; Ide, C. Alginate Enhances Elongation of Early Regenerating Axons in Spinal Cord of Young Rats. Tissue Eng. 2004, 10, 493-504.

13. Schürks, N.; Wingender, J.; Flemming, H.-C.; Mayer, C. Monomer Composition and Sequence of Alginates from Pseudomonas aeruginosa. Int. J. Biol. Macromol. 2002, 30, 105-111.

14. Zhang, Z.; Yu, G.; Guan, H.; Zhao, X.; Du, Y.; Jiang, X. Preparation and Structure Elucidation of Alginate Oligosaccharides Degraded by Alginate Lyase fromVibriosp. 510. Carbohydr. Res. 2004, 399, 1475-1481.

15. Iwamoto, Y. Iriyama, K. Osatomi, K. Oda, T. Muramatsu, T. Primary Structure and Chemical Modification of Some Amino Acid Residues of Bifunctional Alginate Lyase from a Marine Bacterium Pseudoalteromonas sp. strain no. 2721. J. Protein Chem. 2002, 21, 455-463.

16. Jacobs, A.; Dahlman, O. Enhancement of the Quality of MALDI mass Spectra of Highly Acidic Oligosaccharides by Using a Nafion-Coated Probe. Anal. Chem. 2001, 73, 405-410.

17. Wang, Y; Yu, G.; Zhao, X.; Guan, H.; Du, Y. Preparation and Structural Characterization of Several Oligoguluronic Acids. Chem. J. Chin. Univ. 2005, 26, 179-183.

18. Campa, C.; Oust, A.; Skjak-Braek, G.; Paulsen, B. S.; Paoletti, S.; Christensen, B. E.; Balance, S. Determination of Average Degree of Polymerization and Distribution of Oligosaccharides in a Partially Acid-Hydrolyzed Homopolysaccharide: A Comparison of Four Experimental Methods Applied to Mannuronan. J. Chromatogr. A 2004, 1026, 271-281.

19. Chai, W.; Luo, J.; Lim, C. K.; Lawson, A. M. Characterization of Heparin Oligosaccharide Mixtures as Ammonium Salts Using Electrospray Mass Spectrometry. Anal. Chem. 1998, 70, 2060-2066.

20. Zaia, J.; Costello, C. E. Compositional Analysis of Glycosaminoglycans by Electrospray Mass Spectrometry. Anal. Chem. 2001, 73, 233-239.

21. Zaia, J.; McClellan, J. E.; Costello, C. E. Tandem Mass Spectrometric Determination of the 4S/6S Sulfate Sequence in Chondroitin Sulfate Oligosaccharides. Anal. Chem. 2001, 73, 6030-6039.

22. Chai, W.; Piskarev, V.; Lawson, A. M. Negative-Ion Electrospray Mass Spectrometry of Neutral Underivatized Oligosaccharides. Anal. Chem. 2001, 73, 651-657.

23. Chai, W.; Lawson, A. M.; Piskarev, V. Branching Pattern and Sequence Analysis of Underivatized Oligosaccharides by Combined MS/MS of Singly and Doubly Charged Molecular Ions in Negative-Ion Electro- 
spray Mass Spectrometry. J. Am. Soc. Mass Spectrom. 2002, 13, 670679.

24. Leteux, C.; Chai, W.; Nagai, K.; Herbert, C. G.; Lawson, A. M.; Feizi, T. 10E4 Antigen of Scrapie Lesions Contains an Unusual Nonsulfated Heparan Motif. J. Biol. Chem., 2001, 276, 12539-12545.

25. Chai, W.; Leteux, C.; Westling, C.; Lindahl, U.; Feizi, T. Relative Susceptibilities of the Glucosamine-Glucuronic Acid and N-Acetylglucosamine-Glucuronic Acid Linkages to Heparin Lyase III. Biochemistry 2004, 43, 8590-8599.

26. Shimokawa, T.; Yoshida, S.; Kusakabe, I.; Takeuchi, T.; Murata, K.; Kobayashi, H. Some Properties and Action Mode of $(1 \rightarrow 4)-\alpha$-LGuluronan Lyase from Enterobacter cloacae M-1. Carbohydr. Res. 1997, 304, 125-132.

27. Domon, B.; Costello, C. E. A Systematic Nomenclature for Carbohydrate Fragmentation in FAB-MS/MS Spectra of Glycoconjugates. Glycoconj. J. 1988, 5, 397-409.

28. Wheeler, S. F.; Harvey, D. J. Negative Ion Mass Spectrometry of Sialylated Carbohydrates: Discrimination of N-Acetylneuraminic Acid
Linkages by MALDI-TOF and ESI-TOF Mass Spectrometry. Anal. Chem. 2000, 72, 5027-5039.

29. Chai, W., Piskarev, V. E., Mulloy, B., Liu, Y., Evans, P., Osborn, H. M. I., Lawson, A. M. Analysis of Chain and Blood-Group Type, and Branching Pattern of Sialylated Oligosaccharides by Negative-Ion Electrospray Tandem Mass Spectrometry. Anal. Chem. in press.

30. Smidsrod, O.; Haug, A.; Larsen, B. The Influence of $\mathrm{pH}$ on the Rate of Hydrolysis of Acidic Polysaccharides. Acta Chem. Scand. 1966, 20, $1026-1034$

31. Atkins, E. D.; Mackie, W.; Smolko, E. E. Crystalline Structures of Alginic Acids. Nature 1970, 225, 626-628.

32. Atkins, E. D.; Nieduszynski, I. A.; Mackie, W.; Parker, K. D.; Smolko, E. E. Structural Components of Alginic Acid. I. The Crystalline Structure of Poly- $\beta$-D-mMnnuronic Acid. Results of X-ray Diffraction and Polarized Infrared Studies. Biopolymers 1973, 12, 1865-1878.

33. Atkins, E. D.; Nieduszynski, I. A.; Mackie, W.; Parker, K. D.; Smolko, E. E. Structural Components of Alginic acid. II. The Crystalline Structure of Poly- $\alpha$-L-Guluronic Acid. Results of X-ray Diffraction and Polarized Infrared Studies. Biopolymers 1973, 12, 1879-1887. 